\title{
PEMANFAATAN SISTEM REGISTRASI ALAT BERAT DI DUNIA KONSTRUKSI
}

\author{
Arisal Riadhi Arifin', Susy Fatena Rostiyanti² \\ ${ }^{1}$ Program Studi Teknik Sipil, Universitas Tarumanagara, Jakarta \\ Email: arisalriadhi92@gmail.com \\ ${ }^{2}$ Program Studi Teknik Sipil, Universitas Tarumanagara, Jakarta \\ Email: srostiya@gmail.com
}

Masuk: dd-mm-yyyy, revisi: dd-mm-yyyy, diterima untuk diterbitkan: dd-mm-yyyy

\begin{abstract}
ABSTRAK
Sistem Registrasi Alat Berat Konstruksi (ABK) adalah sistem untuk mengatur segala hal terkait alat berat yang digunakan dalam pekerjaan. Pada pelaksanaannya, alat berat yang teregistrasi jauh dari harapan sehingga perlu dilakukan pengembangan pada sistem registrasi itu sendiri agar bisa dimanfaatkan masyarakat jasa konstruksi. Metode penelitian yang dipakai dalam penelitian ini menggunakan beberapa literatur, penelitian terdahulu, studi pustaka, dan melakukan perbandingan pada sistem di negara lain serta melihat dari peraturan yang ada untuk membentuk pertanyaan kuesioner kemudian menyebarkannya. Data yang diperoleh dari responden dimasukkan ke dalam aplikasi analisis data statistik lalu dilakukan uji validitas, uji reliabilitas, dan uji korelasi. Hasil analisis kemudian dilakukan pembahasan dan divalidasi oleh pakar. Hasil yang didapat dari penelitian ini ditemukan beberapa variabel yang perlu dikembangkan pada dimensi sistem, serta aturan dan kebijakan dalam Sistem Registrasi ABK untuk memperbaiki rantai pasok alat berat konstruksi. Variabel pengembangan tersebut mengacu dari 36 variabel awal. Berdasarkan hasil identifikasi terhadap variabel awal ditemukan 20 variabel yang tidak perlu diteliti, sedangkan 12 variabel lainnya perlu dimasukkan dalam penelitian. Analisis dari 12 variabel tersebut dikembangkan 22 variabel baru dari dimensi sistem, serta aturan dan kebijakan untuk melengkapi 20 variabel awal. Variabel-variabel inilah yang perlu dikembangkan dan dimanfaatkan di dalam Sistem Registrasi Alat Berat Konstruksi.
\end{abstract}

Kata Kunci: Sistem Registrasi Alat Berat Konstruksi (ABK); Rantai Pasok Alat Berat Konstruksi; Masyarakat Jasa Konstruksi

\section{ABSTRACT}

The Construction Heavy Equipment Registration System (Alat Berat Konstruksi, ABK) is a system for managing everything related to heavy equipment used in work. In its implementation, the heavy equipment that is registered is far from expectations so that it is necessary to develop the registration system itself so that the construction service community can use it. The research method used in this study uses some literature, previous research, literature studies, and makes comparisons on systems in other countries and looks at the existing regulations to form questionnaire questions and then disseminates them. Data obtained from respondents were entered into the statistical data analysis application and then tested the validity, reliability test, and correlation test. The results of the analysis are then discussed and validated by experts. The results obtained from this study found several variables that need to be developed in the dimensional system, as well as rules and policies in the ABK Registration System to improve the supply chain of construction heavy equipment. The development variable is the development of 36 initial variables. Based on the results of the assessment of the initial variables found 20 variables that are not necessary, while 12 other variables need to be included in the study. Analysis of 12 variables developed by 22 new variables from the system, as well as rules and policies to complete the initial 20 variables. Variables that need to be developed and used in the Construction Heavy Equipment Registration System.

Keywords: Construction Heavy Equipment Registration System (Alat Berat Konstruksi, ABK); Construction Equipment Supply Chain; Construction Services Society

\section{PENDAHULUAN \\ Latar Belakang}

Pemerintah telah menetapkan pembangunan infrastruktur sebagai salah satu program strategis guna mendorong pertumbuhan ekonomi nasional dengan indikasi kebutuhan investasi infrastruktur tahun 2015-2019 sebesar Rp.4,796 Triliun. Dengan banyaknya pembangunan infrastruktur yang tersebar di seluruh wilayah, saat ini Indonesia berada pada deretan negaranegara yang paling progresif menyelenggarakan konstruksi. 
Proyek konstruksi memiliki kompleksitas relatif tinggi. Kompleksitas tersebut berupa banyaknya pekerjaan yang harus dikerjakan, tingkat kesulitan yang tinggi, banyaknya sumber daya dan pihak terkait proyek yang harus dikelola, tingginya ketidakpastian, dan tingginya risiko. Hal tersebut sering menjadi penyebab keterlambatan pada pelaksanaan proyek konstruksi. Untuk mengatasi keterlambatan yang terjadi pada proyek konstruksi dilakukan langkah atau strategi percepatan proyek (schedule compression) seperti yang telah dijelaskan. Umumnya dilakukan metode crashing dan fast tracking secara bersamaan. Hal ini untuk mendapatkan tingkat percepatan yang terbaik dalam mengatasi keterlambatan pada situasi yang kompleks. Walaupun pada kenyataannya, banyak program percepatan yang kurang berhasil padahal telah mengeluarkan biaya yang tidak sedikit.

Dengan mengurangi metode konvensional, kebutuhan penggunaan alat berat mengalami peningkatan untuk memenuhi tuntutan pekerjaan konstruksi di segi waktu dan teknologi. Maka dari itu, dibutuhkan suatu sistem yang dapat mengendalikan penyelenggaraan rantai pasok konstruksi. Salah satu hal yang perlu diperhatikan adalah kesiapan alat berat konstruksi. Secara umum, alat-alat berat (yang sering dikenal di dalam ilmu Teknik Sipil) merupakan alat yang digunakan untuk membantu manusia dalam melakukan pekerjaan pembangunan suatu struktur bangunan. Alat berat merupakan faktor penting didalam proyek, terutama proyek-proyek konstruksi maupun pertambangan dan kegiatan lainnya dengan skala yang berat (Rostiyanti, 2008). Sayangnya, kesiapan dan pengaturan terkait alat berat belum sepenuhnya dapat dijalankan. Baik pengguna jasa, penyedia jasa, maupun masyarakat jasa konstruksi lainnya belum bisa saling memberikan manfaat bersama dikarenakan belum adanya kebijakan pemerintah terkait pengaturan alat berat konstruksi. Maraknya kasus kecelakaan konstruksi akibat alat berat konstruksi yang dipakai juga menuntut pemerintah untuk segera mengatur kebijakan dan menyusun regulasi terkait dengan alat berat. Berdasarkan hal tersebut, pemerintah menggagas suatu sistem untuk mengendalikan rantai pasok alat berat konstruksi yang salah satu di antaranya adalah sistem registrasi alat berat konstruksi. Tujuan dari sistem tersebut agar pemerintah dapat mengatur dan melihat setiap pergerakan, kondisi kelayakan operasi serta produksi alat berat.

Seiring pelaksanaannya, sistem registrasi alat berat konstruksi ini belum mampu menjadi kebutuhan dan kewajiban bagi para pemilik alat berat sehingga data yang diperoleh dari masingmasing anggota yang terdaftar tidak bisa dilakukan validasi sepenuhnya. Maka dari itu sistem ini perlu dikembangkan melalui penelitian untuk mengidentifikasi masalah-masalah yang terjadi di lapangan. Baik permasalahan yang terdapat pada sistemnya, maupun perilaku para pemilik alat berat saat pengisian data registrasi. Agar sistem ini dapat disempurnakan dan dapat memberi manfaat bagi seluruh pelaku usaha jasa konstruksi.

\section{Rumusan Masalah}

Variabel data dan informasi yang tersedia dalam Sistem Registrasi Alat Berat Konstruksi tidak lengkap karena tidak sepenuhnya diisi oleh pemilik alat berat konstruksi. Adapun Sistem Registrasi Alat Berat Konstruksi yang dibangun tidak dikembangkan dan diawasi dengan baik karena sistem yang dibuat hanya untuk keperluan pemerintah sehingga terdapat variabel data yang perlu ditambah.

\section{Batasan Penelitian}

Ruang lingkup ini terbatas pada konseptual pengembangan sistem registrasi alat berat konstruksi yang dimiliki pengguna jasa, penyedia jasa, sub penyedia jasa, rental alat berat maupun perorangan 


\section{METODE PENELITIAN}

\section{Jenis Data}

Data-data yang digunakan dan terdapat pada penelitian ini terdiri atas 2 (dua) jenis, yaitu data kualitatif dan data kuantitatif.

\section{Data Kualitatif}

Data kualitatif merupakan data yang tidak bisa dilihat, dihitung secara langsung, hanya berdasarkan pengamatan-pengamatan tertentu. Pengukuran data kualitatif pada penelitian ini menggunakan dimensi pada sistem dan aturan/kebijakan. Menurut Soeratno dan Arsyad (1993), sekalipun data kualitatif tidak berbentuk angka namun bukan berarti data itu tidak dapat digunakan pada analisis statistik.

\section{Data Kuantitatif}

Data kuantitatif merupakan data yang dinyatakan dalam bentuk angka dari hasil perhitungan dan pengukuran pada data kualitatif sehingga menghasilkan data yang bersifat numerik. Menurut Siyoto dan Sodik (2015), data kuantitatif diklasifikasikan menjadi dua yaitu data kuantitatif berdasarkan proses atau cara mendapatkannya dan berdasarkan tipe skala pengukuran yang digunakan. Prosedur dalam penelitian kuantitatif di mana peneliti melakukan survei ke sampel atau ke seluruh populasi orang untuk menggambarkan sikap, pendapat, perilaku, atau karakteristik populasi (Creswell, 2005).

\section{Data Penelitian}

Penelitian ini menggunakan data yang diperoleh dari pemerintah selaku pengguna jasa serta stakeholder terkait. Data penelitian ini berupa data informasi alat berat konstruksi yang telah terdaftar dan telah dilakukan proses verifikasi oleh pemerintah di seluruh provinsi di Indonesia. Dalam penelitian ini juga dilakukan pengukuran langsung melalui penyebaran kuesioner dengan menggunakan skala likert (Risnita, 2012) sehingga secara umum dapat dinyatakan bahwa penelitian ini menggunakan data primer dan data sekunder sebagai sumber data utamanya.

a. Pengumpulan Data Primer, yaitu data yang dikumpulkan dan diolah sendiri oleh peneliti langsung dari subjek atau objek penelitian. Penelitian ini menggunakan data primer dengan menggunakan metode kuesioner. Sumber data primer adalah sumber data yang langsung memberikan data kepada pengumpul data (Sugiyono, 2013).

b. Pengumpulan Data Sekunder, yaitu data yang didapatkan tidak secara langsung dari objek atau subjek penelitian dengan menggunakan data informasi alat berat konstruksi. Data sekunder adalah sumber data yang tidak langsung memberikan data kepada pengumpul data, tetapi melihat orang lain atau dengan dokumen (Sugiyono, 2013).

\section{Variabel Penelitian}

Variabel pada penelitian ini diperoleh berdasarkan beberapa literatur dan penelitian terdahulu serta studi pustaka. Pembuatan kuesioner dilakukan dengan cara mengadaptasi pertanyaan-pertanyaan yang ada dalam penelitian terdahulu dan melakukan perbandingan pada sistem yang telah ada di negara lain serta melihat dari sudut pandang peraturan-peraturan yang ada dan yang berhubungan dengan topik penelitian sebagai dasar pembentukan variabel bebas (variabel X). Pada tabel 1 berikut ini adalah variabel - variabel bebas (Xi) yang akan dipakai untuk penelitian ini dengan variabel terikat (Y) adalah "Sistem Registrasi Alat Berat Konstruksi layak menjadi bagian dari sistem rantai pasok alat berat konstruksi" 
Tabel 1 Variabel Bebas Penelitian

\begin{tabular}{|c|c|c|}
\hline No. & Jenis Variabel & Sumber \\
\hline $\mathbf{X 1}$ & $\begin{array}{l}\text { Pemilik Alat Berat Konstruksi wajib meregistrasi semua alat berat konstruksi yang } \\
\text { dimiliki }\end{array}$ & $\begin{array}{l}\text { Regulasi Amerika } \\
\text { terkait Alat Berat }\end{array}$ \\
\hline $\mathbf{X} 2$ & $\begin{array}{l}\text { Diperlukan sosialisasi menyeluruh ke semua masyarakat jasa konstruksi terkait pentingnya } \\
\text { registrasi ABK }\end{array}$ & $\begin{array}{l}\text { Kegiatan Direktorat } \\
\text { Jenderal Bina } \\
\text { Konstruksi }\end{array}$ \\
\hline $\mathbf{X 3}$ & $\begin{array}{l}\text { Diperlukan sosialisasi mengenai aturan UU No. } 2 \text { Tahun } 2017 \text { pasal } 83 \text { ayat (3) bahwa } \\
\text { setiap Pengguna Jasa dan Penyedia Jasa serta institusi yang terkait dengan Jasa Konstruksi } \\
\text { harus memberikan data dan informasi dalam rangka tugas pembinaan dan layanan }\end{array}$ & $\begin{array}{l}\text { Kegiatan Direktorat } \\
\text { Jenderal Bina } \\
\text { Konstruksi }\end{array}$ \\
\hline X4 & $\begin{array}{l}\text { Verifikasi dan Pengawasan terhadap kesesuaian data pemilik ABK dengan kondisi riil di } \\
\text { lapangan dilakukan Kelompok Kerja (Pokja) atau Satuan Kerja (Satker) }\end{array}$ & $\begin{array}{l}\text { Sistem Registrasi Alat } \\
\text { Berat Amerika }\end{array}$ \\
\hline X5 & $\begin{array}{l}\text { Pemilik Alat Berat Konstruksi wajib mengupdate data kondisi alat yang dimilikinya secara } \\
\text { berkala atau mengupdate setiap ABK tersebut berpindah lokasi pekerjaan }\end{array}$ & $\begin{array}{l}\text { Sistem Registrasi Alat } \\
\text { Berat Amerika } \\
\end{array}$ \\
\hline X6 & $\begin{array}{l}\text { Setiap ABK yang bekerja harus melampirkan sertifikasi atau memenuhi kelaikan operasi } \\
\text { yang dibuktikan melalui pengujian }\end{array}$ & $\begin{array}{c}\text { Surat Izin Laik Operasi } \\
\text { ABK } \\
\end{array}$ \\
\hline $\mathbf{X} 7$ & $\begin{array}{l}\text { Setiap ABK yang diregistrasi wajib melampirkan Foto Alat Berat dan Sertifikat Kelaikan } \\
\text { Alat Berat }\end{array}$ & $\begin{array}{l}\text { Regulasi Alat Berat } \\
\text { Pemerintah Australia }\end{array}$ \\
\hline X8 & $\begin{array}{l}\text { Pemilik Alat Berat Konstruksi wajib mengisi alamat perusahaan, kota perusahaan dan } \\
\text { nomor kontak perusahaan/ penanggungjawab yang dapat dihubungi }\end{array}$ & $\begin{array}{l}\text { Sistem Registrasi Alat } \\
\text { Berat Amerika }\end{array}$ \\
\hline X9 & Setiap ABK yang diregistrasi wajib mengisi kapasitas angkat/angkut tiap alat & $\begin{array}{l}\text { Regulasi Alat Berat } \\
\text { Pemerintah Australia }\end{array}$ \\
\hline $\mathbf{X 1 0}$ & Setiap ABK yang diregistrasi wajib mengisi Nomor Seri dan Nomor Mesin & $\begin{array}{l}\text { Regulasi Alat Berat } \\
\text { Pemerintah Australia }\end{array}$ \\
\hline $\mathbf{X 1 1}$ & Setiap ABK yang diregistrasi wajib melampirkan Faktur Pajak & $\begin{array}{l}\text { Regulasi Alat Berat } \\
\text { Pemerintah Australia }\end{array}$ \\
\hline $\mathbf{X 1 2}$ & Setiap Pemilik ABK wajib mengisi tahun pembuatan alat berat yang dimiliki & $\begin{array}{l}\text { Regulasi Alat Berat } \\
\text { Pemerintah Australia }\end{array}$ \\
\hline $\mathbf{X 1 3}$ & Kategori dan subkategori pada Sistem Registrasi ABK perlu diperbarui & $\begin{array}{c}\text { Katalog Alat Berat } \\
\text { Konstruksi 2013, } \\
\text { Kementerian Pekerjaan } \\
\text { Umum dan Perumahan } \\
\text { Rakyat } \\
\end{array}$ \\
\hline X14 & Diperlukan fitur pencarian ABK yang tersedia untuk disewakan & $\begin{array}{l}\text { Sistem Registrasi Alat } \\
\text { Berat Amerika }\end{array}$ \\
\hline $\mathbf{X 1 5}$ & $\begin{array}{l}\text { Sistem Registrasi ABK perlu menyertakan portal berita, kegiatan atau informasi yang } \\
\text { terkait Alat Berat }\end{array}$ & $\begin{array}{l}\text { Sistem Registrasi Alat } \\
\text { Berat Amerika }\end{array}$ \\
\hline $\mathbf{X 1 6}$ & Sistem Registrasi ABK perlu dibuat aplikasi berbasis mobile phone & $\begin{array}{l}\text { Sistem Registrasi Alat } \\
\text { Berat Eropa }\end{array}$ \\
\hline $\mathbf{X 1 7}$ & Setiap Pemilik ABK wajib mengisi frekuensi berkala perawatan alat berat yang dimiliki & $\begin{array}{l}\text { Regulasi Alat Berat } \\
\text { Pemerintah Australia } \\
\end{array}$ \\
\hline $\mathbf{X 1 8}$ & Setiap Pemilik ABK perlu dilengkapi asuransi alat berat yang dimiliki & $\begin{array}{l}\text { Regulasi Alat Berat } \\
\text { Pemerintah Australia }\end{array}$ \\
\hline $\mathbf{X 1 9}$ & $\begin{array}{l}\text { Sistem Registrasi ABK juga seharusnya menyertakan Registrasi Operator ABK yang } \\
\text { terlisensi di Kementerian Ketengakerjaan RI }\end{array}$ & $\begin{array}{c}\text { Kementerian Tenaga } \\
\text { Kerja dan Transmigrasi } \\
\text { R.I., Direktorat Jenderal } \\
\text { Pembinaan Pengawasan } \\
\text { Ketenagakerjaan } \\
\end{array}$ \\
\hline $\mathbf{X} 20$ & $\begin{array}{l}\text { ABK terdaftar harus dioperasikan dengan operator yang memiliki SIO (Surat Izin } \\
\text { Operator) }\end{array}$ & $\begin{array}{c}\text { Kementerian Tenaga } \\
\text { Kerja dan Transmigrasi } \\
\text { R.I., Direktorat Jenderal } \\
\text { Pembinaan Pengawasan } \\
\text { Ketenagakerjaan } \\
\end{array}$ \\
\hline $\mathbf{X} 21$ & Diperlukan aturan mengenai sistem pengamanan dan pemeliharaan $\mathrm{ABK}$ & $\begin{array}{l}\text { pasal } 3 \text { ayat (1) UU No. } \\
1 \text { Tahun } 1970 \text { tentang } \\
\text { keselamatan konstruksi }\end{array}$ \\
\hline $\mathbf{X} 22$ & $\begin{array}{l}\text { Sistem Registrasi ABK perlu melampirkan aturan mengenai Keselamatan Kerja yang } \\
\text { dapat menimbulkan bahaya kecelakaan }\end{array}$ & $\begin{array}{c}\text { pasal } 4 \text { ayat (1) UU No. } \\
1 \text { Tahun } 1970 \text { tentang } \\
\text { keselamatan konstruksi }\end{array}$ \\
\hline $\mathbf{X} 23$ & Semua Alat Berat yang bekerja di proyek konstruksi wajib memasang Alat Pelacak (GPS) & $\begin{array}{l}\text { Sistem Registrasi Alat } \\
\text { Berat Amerika }\end{array}$ \\
\hline
\end{tabular}




\section{Metode Pengumpulan dan Analisis}

Salah satu komponen yang penting dalam penelitian adalah proses peneliti dalam pengumpulan data. Pengumpulan data dilakukan untuk memperoleh informasi yang dibutuhkan dalam rangka mencapai tujuan penelitian. Menurut Siyoto dan Sodik (2015), data merupakan sesuatu yang dikumpulkan oleh peneliti berupa fakta empiris yang digunakan untuk memecahkan masalah atau menjawab pertanyaan penelitian. Selain untuk memecahkan masalah, data juga menurut Soeratno dan Arsyad (1993) perlu diadakan dalam rangka menguji suatu hipotesis yang berdasar pada suatu model. Adapun wujud data dapat berbentuk sebagai angka, huruf, gambar, suara, suatu keadaan, atau simbol-simbol lainnya. Data belum dapat bermakna bagi penerimanya kecuali telah melalui suatu pengolahan sehingga menjadi sebuah informasi yang kemudian dapat dimengerti. Kesalahan dalam proses pengumpulan data akan membuat proses analisis menjadi sulit jika terjadi kesalahan pengumpulan data sehingga hasil dan kesimpulan yang didapat pun akan menjadi rancu.

Metode Analisis Data pada penelitian ini menggunakan metode pengolahan di aplikasi analisis data statistik SPSS (Sarwono, 2012) yang akan menghasilkan data yang bisa dan akan dianalisis di dalam software tersebut. Software ini akan membantu perhitungan-perhitungan yang akan dilakukan agar bisa menghasilkan hasil yang akurat dan menghindari "human error". Metode analisis data adalah upaya atau cara untuk mengolah data menjadi informasi sehingga karakteristik data tersebut bisa dipahami dan bermanfaat untuk solusi permasalahan, tertutama masalah yang berkaitan dengan penelitian. Atau definisi lain dari analisis data yaitu kegiatan yang dilakukan untuk menubah data hasil dari penelitian menjadi informasi yang nantinya bisa dipergunakan dalam mengambil kesimpulan. Adapun konsep analisis data yang digunakan yaitu Uji Pilot Sample, Uji Validitas, Uji Reliabilitas (Cronbach, 1951), Analisis Korelasi (Widodo, 2015), Uji Normalitas (Nurudin, 2014).

\section{HASIL DAN PEMBAHASAN}

\section{Pilot Sample}

Pilot sample digunakan untuk mengecek hasil validitas dan reliabilitias dari variabel kuesioner yang telah terbentuk. Dengan menggunakan responden yang terkontrol (control group) maka bisa ditentukan variabel apa saja yang perlu diperbaiki atau dieliminasi. Berdasarkan hasil tes reliabilitas, ditunjukan bahwa nilai Cronbach's Alpha adalah 0,959 dan nilai validitas terkecil (0.463) lebih tinggi dari batas yang diambil dari tabel upper critical limit spearman rank correlation yaitu 0.446 . Hasil ini menunjukkan pertanyaan-pertanyaan kuesioner sudah baik dan dapat diterima.

\section{Hasil Uji Validitas dan Reliabilitas Terhadap Kuesioner}

Uji validitas dilakukan terhadap instrumen uji coba variabel $\mathrm{X}$ yang merupakan variabel bebas dan variabel Y yang merupakan variabel terikat. Hasil analisis uji validitas menunjukkan bahwa nilai koefisien korelasi (ri) untuk masing-masing pertanyaan memiliki nilai koefisien lebih dari 0,180, dengan koefisien korelasi (ri) terletak pada kolom "Corrected Item-Total Correlation". Karena tiap pertanyaan sudah memiliki nilai koefisien di atas 0,180 maka bisa disimpulkan bahwa pertanyaan-pertanyaan pada kuesioner sudah valid untuk responden berjumlah 85 dengan nilai signifikansi 0,05. Hasil koefisien korelasi (ri) untuk tiap pertanyaan bisa dilihat pada tabel di bawah ini. Hasil uji reliabilitas yang dilakukan juga menunjukkan nilai cronbach's alpha sebesar 0.948 yang menunjukkan kuesioner memasuki katagori "Very Good". 


\section{Hasil Uji Korelasi Terhadap Kuesioner}

Pada tabel di bawah dapat dilihat adalah variabel bebas (variabel $\mathrm{X}$ ) hasil uji korelasi yang memiliki hubungan yang cukup signifikan dengan variabel terikat (variabel Y).

Tabel 2 Hasil Uji Korelasi

\begin{tabular}{llccccccccccc}
\hline & $\mathrm{X} 1$ & $\mathrm{X} 2$ & $\mathrm{X} 3$ & $\mathrm{X} 4$ & $\mathrm{X} 5$ & $\mathrm{X} 6$ & $\mathrm{X} 7$ & $\mathrm{X} 8$ & $\mathrm{X} 9$ & $\mathrm{X} 10$ & $\mathrm{X} 11$ \\
\hline $\mathrm{Y} 1$ & $\begin{array}{l}\text { Pearson } \\
\text { Correlation }\end{array}$ &, $428^{* *}$ &, $312^{* *}$ &, $372^{* *}$ &, $430^{* *}$ &, $318^{* *}$ &, $507^{* *}$ &, $515^{* *}$ &, $594^{* *}$ &, $393^{* *}$ &, $393^{* *}$ &, $363^{* *}$ \\
\hline $\begin{array}{l}\text { Sig. (2- } \\
\text { tailed) }\end{array}$ &, 000 &, 004 &, 000 &, 000 &, 003 &, 000 &, 000 &, 000 &, 000 &, 000 &, 001 \\
\hline & $\mathrm{N}$ & 85 & 85 & 85 & 85 & 85 & 85 & 85 & 85 & 85 & 85 & 85 \\
\hline$* *$ Correlation is significant at the 0.01 level (2-tailed). & & & & & & \\
$*$ *. Correlation is significant at the 0.05 level (2-tailed). & & & & & &
\end{tabular}

\begin{tabular}{|c|c|c|c|c|c|c|c|c|c|c|c|c|}
\hline & & $\mathrm{X} 12$ & $\mathrm{X} 13$ & X14 & $\mathrm{X} 15$ & $\mathrm{X} 16$ & $\mathrm{X} 17$ & $\mathrm{X} 18$ & X19 & $\mathrm{X} 21$ & $\mathrm{X} 22$ & $\mathrm{X} 23$ \\
\hline \multirow[t]{3}{*}{$\mathrm{Y} 1$} & $\begin{array}{l}\text { Pearson } \\
\text { Correlation } \\
\end{array}$ &, $473^{* *}$ &, $502^{* *}$ &, $444^{* *}$ &, $487^{* *}$ &, $521^{* *}$ &, $342^{* *}$ &, $332^{* *}$ &, $385^{* *}$ &, $429^{* *}$ &, $550^{* *}$ &, $319^{* *}$ \\
\hline & $\begin{array}{l}\text { Sig. (2- } \\
\text { tailed) }\end{array}$ & ,000 & ,000 & ,000 & ,000 & ,000 & 001 & ,002 & ,000 & ,000 & ,000 & ,003 \\
\hline & $\mathrm{N}$ & 85 & 85 & 85 & 85 & 85 & 85 & 85 & 85 & 85 & 85 & 85 \\
\hline
\end{tabular}

Berdasarkan hasil yang didapat, variabel terikat (variabel Y) memiliki korelasi yang cukup kuat dengan 22 variabel bebas (variabel X). Variabel-variabel bebas dipilih berdasarkan tingkat signifikansinya yaitu 0,05 dan 0,01 . Semakin kuat hubungan korelasinya maka semakin tinggi nilai korelasi Pearson yang dihasilkan, sedangkan semakin kuat hubungan korelasinya maka nilai signifikansinya akan semakin kecil. Hasil terbesar dari uji korelasi adalah variabel bebas X8 dengan korelasi Pearson 0,594 dengan nilai signifikansi 0,00 seperti yang bisa dilihat pada tabel di atas

\section{Wawancara Terstruktur}

Berdasarkan hasil analisis korelasi terhadap kuesioner yang telah dilakukan maka didapatkan 22 variabel dengan faktor terbesar dalam kelayakan Sistem Registrasi Alat Berat Konstruksi menjadi bagian dari rantai pasok konstruksi dan diperlukan pengembangan terhadap fitur-fitur yang tersedia di dalamnya untuk divalidasi oleh pakar. Hasil ini kemudian didiskusikan dengan tiga orang pakar, dengan pakar pertama adalah seorang senior di dunia industri teknik sipil yang saat ini menjabat sebagai Direktur Bina Kelembagaan dan Sumber Daya Jasa Konstruksi di Kementerian Pekerjaan Umum dan Perumahan Rakyat dengan pengalaman kerja 32 tahun. Pakar yang kedua merupakan Pejabat Fungsional Pembina Jasa Konstruksi Ahli Madya dari Direktorat Bina Kelembagaan dan Sumber Daya Jasa Konstruksi yang dan pernah menjadi pembicara dalam perihal Sistem Registrasi Alat Berat Konstruksi di Kementerian PUPR dan mempunyai pengalaman 32 tahun dalam menangani aturan dan kebijakan dalam dunia teknik sipil, dengan pakar ketiga juga merupakan Kepala Seksi Standar dan Pedoman, Direktorat Jenderal Bina Kelembagaan dan Sumber Daya Jasa Konstruksi yang merupakan salah satu pencetus Sistem Informasi Material dan Peralatan Konstruksi, dengan pengalaman selama 7 tahun dalam perihal menangani permasalahan material dan peralatan di dunia konstruksi.

Melalui diskusi dengan pakar melalui wawancara terstruktur, para pakar diminta untuk melakukan validasi terhadap 22 variabel hasil analisis dan pembahasan, dimana para responden meminta 
adanya pengembangan di 22 variabel tersebut agar selanjutnya dapat dimanfaatkan di dalam Sistem Registrasi Alat Berat Konstruksi. Peneliti juga turut memberikan pendapat dan solusi di setiap variabel untuk memudahkan proses validasi agar para pakar dapat mengetahui lebih jelas mengapa variabel tersebut dibutuhkan pengembangan. Hasilnya, para pakar menyetujui semua variabel untuk dilakukan pengembangan agar bisa dinyatakan layak sebagai bagian dari sistem rantai pasok alat berat konstruksi. Secara umum, para pakar juga menyetujui solusi dan pendapat yang diberikan oleh peneliti.

\section{KESIMPULAN DAN SARAN}

Kesimpulan yang bisa diambil dari penelitian terkait pengembangan pemanfaatan Sistem Registrasi Alat Berat Konstruksi ini adalah:

a. Melalui uji analisis dari data survei yang didapatkan melalui penelitian survei bermetode kuesioner, maka ada 22 variabel bebas di hasil analisis yang memiliki hubungan korelasi paling kuat terhadap variabel terikat. Sistem Registrasi Alat Berat Konstruksi layak menjadi bagian dari sistem rantai pasok alat berat konstruksi yang penting bagi masyarakat jasa konstruksi.

b. Variabel yang tidak lulus hasil uji korelasi adalah variabel X20, yaitu ABK terdaftar harus dioperasikan dengan operator yang memiliki SIO (Surat Izin Operator).

c. Secara keseluruhan, para pakar setuju terhadap variabel yang diinginkan responden dengan usulan solusi tiap variabel hasil analisis dan pembahasan. Solusi tambahan dari pakar hanya terdapat pada empat variabel.

Berdasarkan penelitian terkait pengembangan pemanfaatan Sistem Registrasi Alat Berat Konstruksi yang telah dilakukan, maka bisa diberikan saran sebagai berikut:

a. Berdasarkan penelitian yang dilakukan terhadap masing-masing variabel yang ada di dalam sistem registrasi alat berat konstruksi didapatkan beberapa item pertanyaan yang belum dilengkapi oleh pemilik alat berat konstruksi. Setelah dilakukan perhitungan penjumlahan kelengkapan tiap variabel pada sistem ditemukan kekurangan data yang besar sehingga perlu pemeriksaan lebih lanjut terhadap variabel yang mengalami kekurangan data agar Sistem Registrasi ABK bisa direvisi lagi menjadi sistem yang lebih baik, dan tentunya bisa dilakukan lagi penambahan terhadap variabel pada sistem bila ada hal lain yang perlu atau wajib dimasukkan.

b. Dalam mengatur rantai pasok alat berat konstruksi diperlukan pengawasan menangani variabel-variabel yang terdapat pada dimensi sistem informasi ABK dan dimensi Aturan/Kebijakan tersebut di atas karena berdasarkan analisis yang telah dilakukan, variabel-variabel inilah yang menurut responden perlu dikembangkan dengan baik di dalam Sistem Registrasi Alat Berat Konstruksi yang tersedia saat ini.

c. Sistem Registrasi Alat Berat Konstruksi sangat memerlukan pengembangan, agar hasil pada penelitian pada topik ini dapat memuaskan semua pihak. Jika diperlukan penelitian lanjutan pada topik atau memiliki topik yang sifatnya serupa dengan penelitian ini, disarankan agar bisa menggunakan analisis-analisis atau metode-metode lain yang tidak digunakan dalam penelitian ini, tergantung jenis data yang dimiliki berupa nominal, ordinal, atau interval agar hasil pada penelitian pada topik ini dapat memuaskan semua pihak, termasuk membantu pemerintah meningkatkan kualitas infrastruktur di Indonesia. 


\section{REFERENSI}

Creswell, J. (2005). Educational Research: Planning, conducting, and evaluating quantitative and qualitative research. New Yersey, USA: Pearson Education Ltd, 354.

Cronbach. (1951). Coefficient Alpha and the Internal Structure of Test, Psychometrika, Vol. 16, No. 3, 297-334.

Nurudin, M., Mara, Novita M., Kusnandar, D. (2014). Ukuran Sampel Dan Distribusi Sampling Dari Beberapa Variabel Random Kontinu. Pontianak: L Buletin Ilmiah Mat. Stat. dan Terapannya (Bimaster) Volume 03, No. 1.

Risnita. (2012). Pengembangan Skala Model Likert. Jurnal Edu-Bio. Vol 3: 86-98.

Rostiyanti, Susy F. (2008). Alat Berat Untuk Proyek Konstruksi. Jakarta: Rineka Cipta, 1, 1-2.

Sarwono. (2012). Teori, Aplikasi, Prsedur, Analisis untuk Riset Skripsi, Tesis dan Disertai Menggunakan SPSS. Jakarta: PT. Elex Media Komputindo.

Sugiyono. (2013). Metode Penelitian Kuantitatif Kualitatif Dan R\&D. Bandung: Alfabeta, 225.

Siyoto, Sandu dan Muhammad Ali Sodik. (2015). Dasar Metodologi Penelitian. Yogyakarta: Literasi Media Publishing.

Soeratno dan Lincolin A. (1993). Metode Penelitian untuk Ekonomi dan Bisnis. Yogyakarta: UPP Akademi Manajemen Perusahaan YKPN.

Widodo, R.S. (2015). Analisis Pelanggaran Kewajiban Pengguna Jasa Berdasarkan Kontrak FIDIC dan AS 4000 - 1997 Pada Proyek Gedung Bertingkat Tinggi di Jakarta. Jakarta: Universitas Tarumanagara. 